\title{
Correction to: Addressing Global Challenges and Quality Education
}

\author{
Carlos Alario-Hoyos (iD, María Jesús Rodríguez-Triana (iD, \\ Maren Scheffel (D), Inmaculada Arnedillo-Sánchez (D), \\ and Sebastian Maximilian Dennerlein (D)
}

\section{Correction to: \\ C. Alario-Hoyos et al. (Eds.): Addressing Global Challenges and Quality Education, LNCS 12315, https://doi.org/10.1007/978-3-030-57717-9}

The original version of the book was inadvertently published with wrong values in Table 2B and Figure 2 in Chapter 31.

The values of emission probability were corrected in 'Table 2B: Emission Probability' and 'Fig. 2. HMM Probabilities from Table $1 \& 2$ ', by replacing the wrong values of emission probability with the appropriate ones to justify the behaviour of the Hidden Markov Model.

Table 2. B: Emission probability

\begin{tabular}{l|l|l|l}
\hline & EO & IR & SAR \\
\hline Dawn & 0.2 & 0.5 & 0.3 \\
\hline Day & 0.7 & 0.2 & 0.1 \\
\hline Dusk & 0.15 & 0.4 & 0.45 \\
\hline Night & 0.1 & 0.4 & 0.5 \\
\hline
\end{tabular}

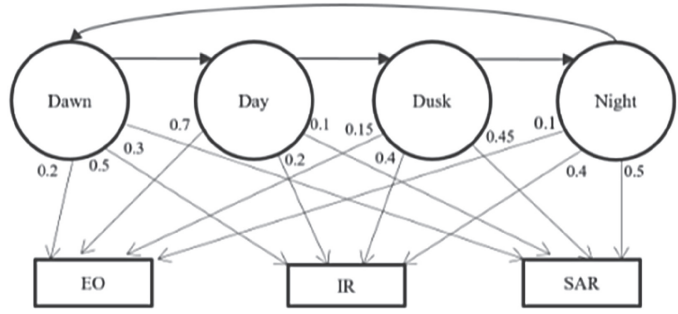

Fig. 2. HMM Probabilities from Table 1 and 2

The original version of the book was inadvertently published with a typo in the name of the second author in Chapter 42. In the contribution it read "Sebastian Dannerlein" but correctly it should have read "Sebastian Dennerlein".

The original version of the book was inadvertently published with a wrong wording of the affiliation of the second author. It read "Technical University of Graz" but correctly it should have read "Graz University of Technology".

The corrected chapters and the book have been updated with the changes.

The updated version of these chapters can be found at

https://doi.org/10.1007/978-3-030-57717-9_31

https://doi.org/10.1007/978-3-030-57717-9_42 